AperTO - Archivio Istituzionale Open Access dell'Università di Torino

\title{
Insights on the natural history of adrenal incidentalomas
}

\section{This is the author's manuscript}

Original Citation:

Availability:

This version is available http://hdl.handle.net/2318/1729210

since 2020-02-20T13:37:05Z

Published version:

DOI:10.7326/M19-1482

Terms of use:

Open Access

Anyone can freely access the full text of works made available as "Open Access". Works made available under a Creative Commons license can be used according to the terms and conditions of said license. Use of all other works requires consent of the right holder (author or publisher) if not exempted from copyright protection by the applicable law. 


\section{INSIGHTS ON THE NATURAL HISTORY OF ADRENAL INCIDENTALOMAS.}

Massimo TERZOLO, MD, Giuseppe REIMONDO, MD, PhD

Internal Medicine, Department of Clinical and Biological Sciences, S. Luigi Gonzaga Hospital, University of Turin, Italy

Address correspondence to:

Prof. Massimo Terzolo

Internal Medicine, S. Luigi Gonzaga Hospital, Regione Gonzole 10, Orbassano (TO) 10043, Italy

Tel: +390116705457

Email: massimo.terzolo@unito.it 
The adrenal incidentaloma is possibly the most common adrenal disorder encountered in everyday practice due to an extensive use of high-resolution cross-sectional imaging that leads frequently to the identification of an adrenal tumor as an incidental finding (1). These clinically inapparent tumors are referred to as adrenal incidentalomas to highlight their unexpected discovery, through a diagnostic work-up done for reasons unrelated to previous suspect of adrenal disease. Studies showed that an adrenal incidentaloma is found in $4 \%$ to $5 \%$ of abdominal CT scans $(1,2)$ and, due to the technological improvement in imaging, frequency is expected to rise in the near future.

The natural history of adrenal incidentalomas is still incompletely understood and this is an important gap of knowledge that hinders appropriate patient care. It is reassuring that most adrenal incidentalomas are benign adrenal adenomas $(1,2)$; however, molecular studies support the concept of multistep adrenocortical tumorigenesis and an evolution from benign cortical adenoma to adrenal carcinoma has been reported (3). Moreover, adrenal adenomas can cause harm to the patients through their capability of secreting autonomously cortisol (4). In principle, this subclinical condition of mild cortisol excess may represent a preliminary stage of overt Cushing's syndrome.

In this context, Elhassan and Colleagues strive to provide meaningful answers to several key questions concerning the natural history of adrenal incidentalomas: i) the risk of tumor growth and possible malignant transformation, ii) the risk of developing clinically overt hormone excess, iii) the risk of morbidity and mortality associated to autonomous cortisol secretion (5). They did a careful meta-analysis of the literature that is very heterogeneous as to the same definition of adrenal incidentaloma and, more importantly, definition of autonomous cortisol secretion and ascertainment of outcomes of interest.

The first finding of the present study is that the risk of tumor growth is limited to a few cases and usually implies an insignificant change in size, being $\geq 10 \mathrm{~mm}$ in only $2.5 \%$ of cases, while malignant transformation was never observed. Cortisol autonomy was tied to an increased attitude to growth. These results confirm robustly, thanks to a comprehensive analysis of the available evidence, what was previously envisaged (6). The novel piece of information is that the chance of growth over time is reduced in larger tumors. Therefore, the outcome of this meta-analysis strongly supports the European Society of Endocrinology and the European Network for the study of Adrenal Tumors (ESE/ENSAT) guidelines that suggested against further imaging follow-up for masses $<4 \mathrm{~cm}$ with clear benign features on imaging studies (7). This meta-analysis should end controversy on the need of routine imaging studies during follow-up (8). As the ESE/ENSAT guidelines indicate, there is an area of uncertainty for 
masses $>4 \mathrm{~cm}$, given the low number of such tumors included in follow-up studies (7). The present results look reassuring also for this subset of tumors that, however, represent less than $10 \%$ of adrenal incidentalomas.

The second finding of the present study is that the risk of developing overt Cushing is virtually absent, while clinical inapparent cortisol autonomy may ensue in $4.3 \%$ of patients with non-functioning tumors. Again, this confirms and extends previous knowledge (6) and demonstrates clearly that autonomous cortisol secretion is not a preliminary stage of overt Cushing's syndrome. This finding fits well with the reported difference in the molecular pathogenesis between adrenal adenomas associated with subclinical or overt cortisol excess (9). The value of repeating hormone work-up during follow-up of patients with adrenal incidentalomas remains matter of contention (8), and the present finding validates the advice of the ESE/ENSAT guidelines against further work-up in patients with non-functioning tumors (7). While the ESE/ENSAT guidelines suggested reassessment in patients with autonomous cortisol secretion with associated comorbidities, the present results seem to limit further the role of hormone testing. It has to been argued, however, that we presently do not know well whether the development of autonomous cortisol secretion during follow-up is tied to clinical consequences $(4,6)$.

The third and more novel finding of the present study is that both patients with nonfunctioning tumors and tumors causing autonomous cortisol secretion have at baseline, and develop during follow-up, comorbidities and incident cardiovascular events. Given that these comorbidities are potentially linked to cortisol excess, it may be surprising to see that also patients with non-functioning tumors are affected, albeit at lower rate than patients exposed to autonomous cortisol secretion. It is presently unknown to what extent this may represent an ascertainment bias, because diseased patients are more likely to undergo imaging tests that may lead to the detection of an adrenal incidentaloma. Alternative explanations could be found in the concept of reverse causality, implying that the metabolic syndrome and/or diabetes are promoting adrenal tumor development (10), or in the concept of a continuum of cortisol secretion from normal to autonomous that escapes precise categorization due to the limitations of endocrine tests. Consequently, also tumors labeled as non-functioning may retain the ability of secreting cortisol in minimal excess.

Elhassan and Colleagues were not able to demonstrate any association between varying degrees of cortisol autonomy and cardiovascular disease, and they found that the risk of dying for any cause, for cardiovascular disease in particular, was similar between patients with nonfunctioning tumors or cortisol-secreting tumors (5). There is evidence, however, that a greater 
degree of cortisol autonomy, heralded by higher cortisol levels after overnight dexamethasone suppression, is linked to increasing cardiovascular risk $(4,6,7)$, but we need more evidence to understand what level of cortisol autonomy is tied to clinical consequences. Answering this question is key to develop adequate decision-making strategies of patients with adrenal incidentalomas concerning the choice between surgery and conservative management.

To conclude, Elhassan and Colleagues provided important insights on the natural history of adrenal incidentalomas that help in solving controversy and informing practice (5). Further studies are needed to associate results of endocrine work-up with clinical phenotyping and patient-centered outcomes for the definition of the optimal treatment of such a frequent endocrine disorder. 


\section{REFERENCES}

1. Aron DC. The adrenal incidentaloma: disease of modern technology and public health problem. Reviews in Endocrine \& Metabolic Disorders 2001; 2:335-342.

2. Grumbach MM, Biller BMK, Braunstein GD, Campbell KK, Carney JA, Godley PA, Harris EL, Lee JKT, Oertel YC, Posner MC, Schlechte JA \& Wieand HS. Management of the clinically inapparent adrenal mass ("Incidentaloma"). Annals of Internal Medicine 2003; 138:424-429.

3. Bernard M-H, Sidhu S, Berger N, Peix J-L, Marsh DJ, Robinson BG, et al. A Case Report in Favor of a Multistep Adrenocortical Tumorigenesis. Journal of Clinical Endocrinology \& Metabolism 2003; 88:998-1001.

4. Terzolo M, Bovio S, Reimondo G, Pia A, Osella G, Borretta G, Angeli A. Subclinical Cushing's syndrome in adrenal incidentalomas. Endocrinology and Metabolism Clinics of North America 2005; 34:423-439.

5. Elhassan YS, Alahdab F, Prete A, Delivanis DA, Khanna A, Prokop L, et al. Natural history of adrenal incidentalomas with and without mild autonomous cortisol excess; a systematic review and meta-analysis. Annals of Internal Medicine 2019

6. Terzolo M, Stigliano A, Chiodini I, Loli P, Furlani L, Arnaldi G, et al. Italian Association of Clinical Endocrinologists. AME position statement on adrenal incidentaloma. European Journal of Endocrinology 2011; 164(6):851-70.

7. Fassnacht M, Arlt W, Bancos I, Dralle H, Newell-Price J, Sahdev A, et al. Management of adrenal incidentalomas: European Society of Endocrinology Clinical Practice Guideline in collaboration with the European Network for the Study of Adrenal Tumors. European Journal of Endocrinology 2016; 175(2):G1-34.

8. Morelli V, Scillitani A, Arosio M, Chiodini I. Follow-up of patients with adrenal incidentaloma, in accordance with the European society of endocrinology guidelines: Could we be safe? Journal of Endocrinological Investigation 2017; 40:331-333.

9. Di Dalmazi G, Kisker C, Calebiro D, Mannelli M, Canu L, Arnaldi G, et al. Novel somatic mutations in the catalytic subunit of the protein kinase A as a cause of adrenal Cushing's syndrome: a European multicentric study. Journal of Clinical Endocrinology \& Metabolism 2014; 99(10):E2923-E2100.

10. Sydney GI, Ioakim KJ, Paschou SA. Insulin resistance and adrenal incidentalomas: A bidirectional relationship. Maturitas. 2019;121:1-6. 


\section{Disclosure}

Massimo Terzolo has received research grant from HRA Pharma and Novartis, and advisory board honoraria from HRA Pharma. 